Aim of the study: To research the demographic and histopathological features of ESCC in southeastern China. Material and methods: We retrospectively reviewed the ESCC cases in the biobank of the National Engineering Centre for Biochip in Shanghai, which cooperates with lots of hospitals and research institutions in southeastern China. The patients were pathologically confirmed as having ESCC. The demographic and histopathological features of these cases were analysed subsequently.

Results: A total of 1317 patients were enrolled. The overall male : female ratio was $2.88: 1.74 .34 \%$ of these cases occurred in people aged between 50-70 years. Dysphagia was the most common symptom, which accounted for $93.40 \%$ of all the patients. Stage II and III were predominant (79.73\%). $72.89 \%$ of patients had a tumour length greater than $3 \mathrm{~cm}$. Most of the tumours $(65.83 \%)$ were located in middle third of the oesophagus. There was a significant difference among the tumour stage, length, and location in different sex groups $(P<0.05)$, but not between different age groups $(P>0.05)$. In males, ESCC is usually located in the lower parts, with a longer tumour length and higher tumour stage. $24.15 \%$ of patients had lymph nodes ratio $($ LNR) $>0.2$.

Conclusions: In our analysis, dysphagia was more common in ESCC patients, to whom more attention should be paid. Additionally, males had a higher incidence, with longer and more distant disease, which gives a poor prognosis.

Key words: oesophageal squamous cell carcinoma, ESCC, characteristics, southeastern China.

Contemp Oncol (Pozn) 2015; 19 (2): 137-141 DOI: 10.5114/wo.2015.51419

\section{The characteristics of oesophageal squamous cell carcinoma: an analysis of 1317 cases in southeastern China}

Yuan-Xi Jiang ${ }^{1}$, Dong-Wei Zhang ${ }^{1}$, Ying Chen ${ }^{1}$, Hui-Hui Sun ${ }^{1}$, Shu-Chang $\mathrm{Xu}^{1^{*}}$, Heng-Jun $\mathrm{Gao}^{2}$

${ }^{1}$ Department of Gastroenterology, Tongji Hospital Affiliated to Tongji University, Shanghai, China

${ }^{2}$ National Engineering Centre for Biochip at Shanghai, Shanghai, China

\section{Introduction}

Oesophageal cancer is the eighth most common cancer and the sixth leading cause of cancer death in the world. In 2002 there were an estimated 462,000 new cases (4.2\% of the total) and 386000 deaths (5.7\% of the total) attributable to oesophageal cancer worldwide [1]. It is primarily composed of two histologic types: squamous cell carcinoma (ESCC) and adenocarcinoma (EA), each apparently having a distinct aetiology [2]. Even though the incidence rate for EA has risen rapidly in the USA and Western Europe [3-5], ESCC is still the predominate type, especially in Asian countries [6-9]. ESCC is related to a variety of factors, such as trace elements [10]. A unique epidemiological feature of oesophageal cancer is its disparate geographic distribution [11]. The southeast of China is not a high incidence area, but it has an increasing trend.

Less than $14 \%$ of oesophageal cancer patients survive longer than five years, despite advances in the fields of oncology and surgery [12]. This is partly because of the biology of the disease and partly because of the delay in diagnosis of the cancer in the majority of patients [13]. Like many other cancers, early diagnosis may mean early treatment, thus giving a better prognosis [14]. In addition, gender, age, histopathological stage, tumour length and location, number of metastatic lymph nodes(LNs), etc. are proposed as independent prognostic indicators [15-20].

The objective of this analysis is to review the demographic and histopathological features in southeastern China with the hope of providing clues for early diagnosis.

\section{Material and methods}

Patients

The data was obtained from the biobank of the National Engineering Centre for Biochip at Shanghai. The biobank is approved by the National Development and Reform Commission of the Chinese government, which cooperates with a number of hospitals and research institutions in southeastern China. All the patients included were pathologically confirmed as ESCC. The local ethics committee approved the procedure.

\section{Assessment of demographic and histopathological features}

The following data was obtained: age, gender, clinical manifestation, histopathological stage, tumour location, tumour length, and metastatic and dissected LNs. The tumoural and nodal status was determined according to the American Joint Committee on Cancer (AJCC) tumour-node-metastasis (TNM) staging system (7 $7^{\text {th }}$ edition) [21]. 
Table 1. Tumour characteristics

\begin{tabular}{|c|c|c|}
\hline Demographics & & $n(\%)$ \\
\hline Gender & $\begin{array}{l}\text { male } \\
\text { female } \\
\text { total }\end{array}$ & $\begin{array}{c}978(74.26) \\
339(25.74) \\
1317(100)\end{array}$ \\
\hline Age (years) & $\begin{array}{l}\text { media } \pm S D \\
\text { range }\end{array}$ & $\begin{array}{c}61.42 \pm 9.60 \\
5-92\end{array}$ \\
\hline Symptom & $\begin{array}{l}\text { dysphagia } \\
\text { chest pain } \\
\text { bleeding } \\
\text { epigastric pain } \\
\text { reflux } \\
\text { hiccups } \\
\text { odynophagia } \\
\text { found mass } \\
\text { heartburn } \\
\text { nausea } \\
\text { hoarseness } \\
\text { total }\end{array}$ & $\begin{array}{c}1230(93.40) \\
101(7.67) \\
12(0.92) \\
10(0.77) \\
82(6.25) \\
20(1.58) \\
112(8.49) \\
42(3.19) \\
32(2.45) \\
17(1.31) \\
8(0.61) \\
1317(100)\end{array}$ \\
\hline $\begin{array}{l}\text { Tumour } \\
\text { location }\end{array}$ & $\begin{array}{l}\text { upper third* } \\
\text { middle third } \\
\text { lower third } \\
\text { total }\end{array}$ & $\begin{array}{c}127(9.64) \\
867(65.83) \\
323(24.53) \\
1317(100)\end{array}$ \\
\hline TNM stage & $\begin{array}{l}\text { IA } \\
\text { IB } \\
\text { II } \\
\text { IIIA } \\
\text { IIIB } \\
\text { IV } \\
\text { total }\end{array}$ & $\begin{array}{c}101(7.67) \\
158(12.00) \\
573(43.51) \\
253(19.21) \\
224(17.01) \\
8(0.61) \\
1317(100)\end{array}$ \\
\hline $\begin{array}{l}\text { Tumour } \\
\text { length }(\mathrm{cm})\end{array}$ & $\begin{array}{l}\text { media } \pm S D \\
\text { range } \\
\leq 3 \mathrm{~cm} \\
>3 \mathrm{~cm} \\
\text { total }\end{array}$ & $\begin{array}{c}4.45 \pm 1.73 \mathrm{~cm} \\
0.2-15 \mathrm{~cm} \\
357(27.11) \\
960(72.89) \\
1317(100)\end{array}$ \\
\hline $\begin{array}{l}\text { No. dissected } \\
\text { LN }\end{array}$ & $\begin{array}{l}\text { media } \pm S D \\
\text { range } \\
<12 \\
\geq 12 \\
\text { total }\end{array}$ & $\begin{array}{c}10.70 \pm 6.29 \\
1-41 \\
856(65.00) \\
461(35.00) \\
1317(100)\end{array}$ \\
\hline $\begin{array}{l}\text { NO. } \\
\text { metastatic LN }\end{array}$ & $\begin{array}{l}\text { media } \pm S D \\
\text { range } \\
0 \\
1-3 \\
\geq 4 \\
\text { total }\end{array}$ & $\begin{array}{c}1.22 \pm 2.16 \\
0-28 \\
708(53.76) \\
471(35.76) \\
138(10.48) \\
1317(100)\end{array}$ \\
\hline LNR & $\begin{array}{l}\leq 0.2 \\
>0.2\end{array}$ & $\begin{array}{l}999(75.85) \\
318(24.15)\end{array}$ \\
\hline
\end{tabular}

\section{Statistical analysis}

Statistical analysis was performed using SPSS software ver17 package. Frequencies were provided using descriptive statistics. Chi-square analysis was used to investigate the significant relationship among different demographic, endoscopic, and pathological features. P-values lower than 0.05 were considered statistically significant.

\section{Results}

The total number of ESCC recorded was 1317; the characteristics are summarized in Table 1.

\section{Gender and age}

A total of 978 males (74.26\%) and 339 females (25.74\%) were found, with a ratio of $2.88: 1$. Patients' ages ranged from 5 to 92 years, with a mean age of $61.42 \pm 9.60$ years; $74.34 \%$ of cases occurred between 50 and 70 years old

\section{Manifestations}

Dysphagia was the most frequent symptom, accounting for $93.40 \%$ of all cases. Apart from dysphagia, other presenting symptoms included the following: chest pain in 101 (7.67\%), bleeding in 12 (0.92\%), epigastric pain in 10 (0.77\%), reflux in 82 (6.25\%), hiccups in 20 (1.58\%), odynophagia in 112 (8.49\%), heartburn in 32 (2.45\%), nausea in 17 (1.31\%), and hoarseness in 8 (0.61\%) patients. 42 (3.19\%) patients had an oesophageal mass found accidently with no symptoms; however, some patients experienced more than one symptom.

\section{Histopathological staging}

Tumour stages were as follows: stage IA, $n=101$ (7.67\%); stage IB, $n=158$ (12.00\%); stage II, $n=573$ (43.51\%); stage IIIA, $n=253$ (19.21\%); stage IIIB, $n=224$ (17.01\%); and stage IV, $n=8(0.61 \%) \cdot \chi^{2}$ analysis demonstrated a significant difference for the histopathological stages between different sex groups $(p=0.000)$, but there was no difference between different age groups ( $p=0.973$ ) (Table 2). Males were more likely to present with higher tumour stage than females (Fig. 1).

\section{Tumour length and location}

The mean tumour length was $4.45 \mathrm{~cm}$ (range $0.2-15 \mathrm{~cm}$ ). $72.89 \%$ of the patients had a tumour length greater than $3 \mathrm{~cm} . \chi^{2}$ analysis demonstrated a significant difference between different sex groups $(p=0.000)$, patients with a tu-

Table 2. The tumour location, length, and stage in different age and sex groups

\begin{tabular}{|c|c|c|c|c|c|c|c|c|c|c|c|c|c|c|c|}
\hline & & \multicolumn{6}{|c|}{ Stage } & \multirow[t]{2}{*}{$P$-value } & \multicolumn{2}{|c|}{ Length } & \multirow[t]{2}{*}{$P$-value } & \multicolumn{3}{|c|}{ Location } & \multirow[t]{2}{*}{$P$-value } \\
\hline & & IA & IB & II & IIIA & IIIB & IV & & $\leq 3 \mathrm{~cm}$ & $>3 \mathrm{~cm}$ & & $\begin{array}{l}\text { upper } \\
\text { parts }\end{array}$ & $\begin{array}{c}\text { middle } \\
\text { parts }\end{array}$ & $\begin{array}{l}\text { lower } \\
\text { parts }\end{array}$ & \\
\hline \multirow{3}{*}{$\begin{array}{l}\text { Age } \\
\text { (years) }\end{array}$} & $<50$ & 7 & 14 & 49 & 18 & 17 & 2 & \multirow[t]{3}{*}{0.973} & 31 & 76 & \multirow[t]{3}{*}{0.399} & 9 & 69 & 29 & \multirow[t]{3}{*}{0.864} \\
\hline & $50-70$ & 76 & 119 & 423 & 189 & 167 & 5 & & 256 & 723 & & 93 & 651 & 235 & \\
\hline & $>70$ & 18 & 25 & 101 & 46 & 40 & 1 & & 70 & 161 & & 25 & 147 & 59 & \\
\hline \multirow[t]{2}{*}{ Sex } & male & 35 & 103 & 444 & 215 & 176 & 5 & \multirow[t]{2}{*}{0.000} & 233 & 745 & \multirow[t]{2}{*}{0.000} & 73 & 637 & 268 & \multirow[t]{2}{*}{0.000} \\
\hline & female & 66 & 55 & 129 & 38 & 48 & 3 & & 124 & 215 & & 54 & 220 & 65 & \\
\hline
\end{tabular}




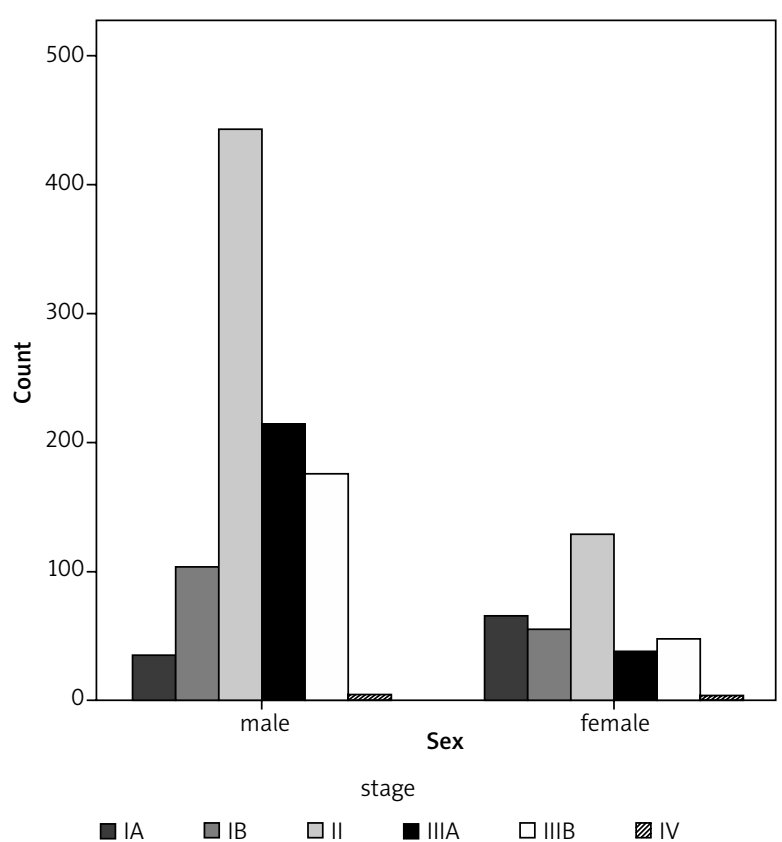

Fig. 1. Stages between different sex groups. Females were more likely to present with localised disease and were less likely to present with distant disease than males $(p=0.000)$

mour length $>3 \mathrm{~cm}$ were more common in males (Fig. 2), but no difference was found between different age groups ( $p=0.399)$ (Table 2).

The tumour was located in the upper third of the oesophagus in 127 (9.64\%) patients, in the middle third in 867 (65.83\%) patients, and in the lower third in 323 (24.53\%) patients. According to chi-square analysis, there was a significant difference between different sex groups ( $p=0.000)$, males were more likely to present with lower parts of the oesophagus and less likely with upper parts than females (Fig. 3). However, there was no difference between different age groups ( $p=0.864$; Table 2).

\section{Metastatic and dissected lymph nodes}

Of the 1317 patients enrolled, 609 were found to have regional $L N$ metastasis, with a rate of $46.24 \%$. A mean (SD) of 10.70 (6.29) (range 1-41) LNs were dissected from each specimen with a mean (SD) number of histopathological positive LNs of 1.22 (2.16). 461 patients (35.00\%) had more than 12 LNs dissected; this cutoff point was employed because it was recommended that at least 12 LNs be removed in the $7^{\text {th }}$ TNM classification [21].

The $L N$ ratio (LNR) measures the number of involved regional LNs compared to the number of dissected LNs. There were 999 patients $(75.85 \%)$ with $L N R \leq 0.2$. A 0.2 ratio of LNR was chosen according to previously published studies, taking into account the more frequent cutoff value identified [22, 23].

\section{Discussion}

ESCC is a common malignancy in China. Although there are increasing studies about ESCC in China, a long delay still exists in diagnosis and treatment of the disease. A few

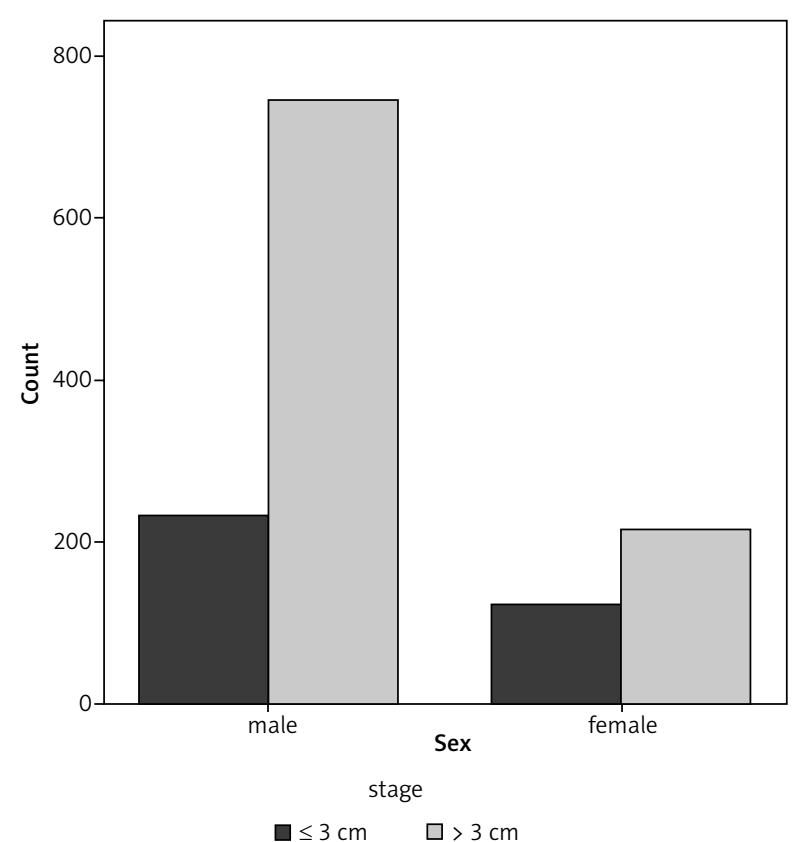

Fig. 2. Length between different sex groups. More than $70 \%$ of patients had a tumour length greater than $3 \mathrm{~cm}$, and it was more common in males $(p=0.000)$

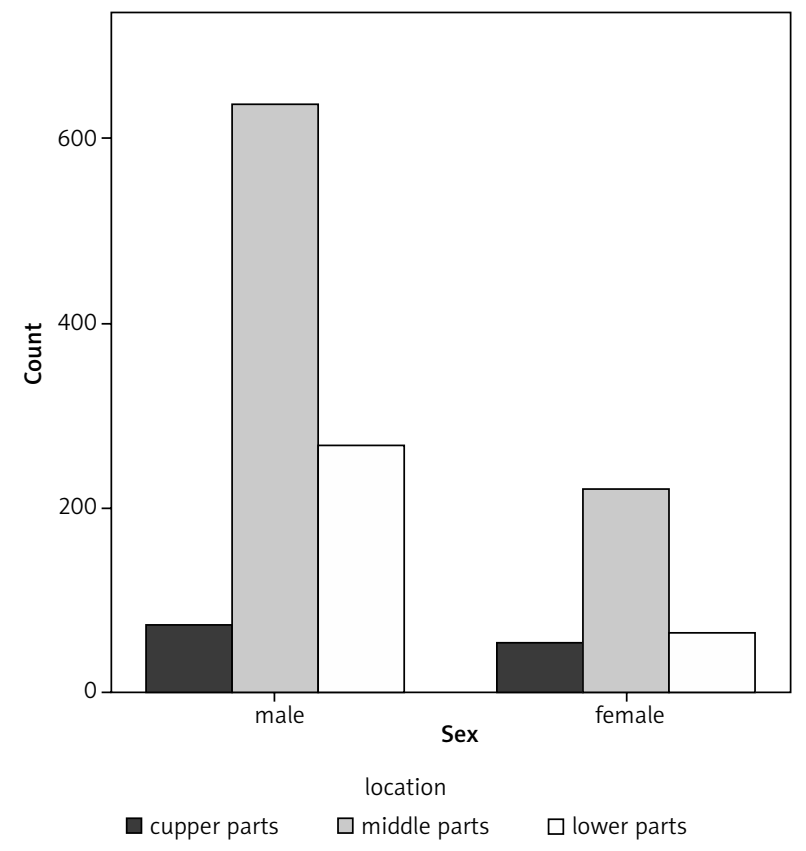

Fig. 3. Location between different sex groups. Males were more likely to present with lower parts of the oesophagus and less likely with upper parts than females $(p=0.000)$

months delay in diagnosis and treatment has a significant influence on the stage of ESCC and, therefore, for the prognosis of the disease [24, 25]. Clearly, a deeper understanding of the characteristics of ESCC in China is required.

Dysphagia is the most typical and striking symptom of ESCC, yet two thirds of patients will tolerate this symptom for a few months before seeking advice [26, 27]. Wang et al. [24] reported that the median symptom-to-treatment de- 
lay was 2.1 months in China. Subasinghe et al. [28] demonstrated that patient delay was the most majority part of the total. In our analysis, dysphagia was the most common symptom, which was present in over $90 \%$ of the patients, a proportion much higher than that in other studies [29]; therefore, more attention should be paid to this symptom.

The prognosis of ESCC correlates well with the stage according to the new TNM classification [21]. The predominant histopathological stages in the current analysis were II and III, comprising $79.73 \%$ of all ESCCS. Females were more likely to present with localised disease than males, which could be due to the fact that females were more likely to seek medical attention [16].

On the other hand, it should be emphasised that the TNM system is only as helpful as its accuracy [30]. To get an accurate idea about $L N$, it is recommended that at least 12 LNs should be removed [21]; however, only 35\% of patients were eligible in our analysis, which may have affected the staging results.

The tumour length of ESCC was once regarded as a prognostic factor, but it was removed from the staging system in 1987 [31]. However, some recent publications suggest that oesophageal tumour length is an important prognostic factor for survival once again; the longer the tumour, the worse the prognosis. The length of $3 \mathrm{~cm}$ was considered as the cutoff point for prediction [32]. In our analysis, it is important to note that more than $70 \%$ of patients had a tumor length greater than $3 \mathrm{~cm}$, and more common in males.

The strength of this analysis is that we carried out comprehensive research on the characteristics of ESCC in southeastern China, which will contribute to early diagnosis and future further study.

In conclusion, dysphagia was more common in ESCC patients in southeastern China, and males had a higher incidence, with longer and more distant disease, which gives a poor prognosis.

The authors wish to acknowledge Yan-yan Lu for her invaluable assistance.

The authors declare no conflict of interest.

\section{References}

1. Parkin D, Bray F, Ferlay J, et al. Global Cancer Statistics, 2002. CA Cancer J Clin 2005; 55: 74-108.

2. Holmes RS, Vaughan TL. Epidemiology and pathogenesis of esophageal cancer. Semin Radiat Oncol 2007; 17: 2-9.

3. Devesa SS, Blot WJ, Fraumeni JF Jr. Changing patterns in the incidence of esophageal and gastric carcinoma in the United States. Cancer 1998; 83: 2049-53.

4. Newnham A, Quinn MJ, Babb P, Kang JY, Majeed A. Trends in oesophageal and gastric cancer incidence, mortality and survival in England and Wales 1971-1998/1999. Aliment Pharmacol Ther 2003; 17: 655-64.

5. Brown LM, Devesa SS, Chow WH. Incidence of adenocarcinoma of the esophagus among white Americans by sex, stage, and age. J Natl Cancer Inst 2008; 100: 1184-7.

6. Fernandes ML, Seow A, Chan YH, Ho KY. Opposing trends in incidence of esophageal squamous cell carcinoma and adenocarci- noma in a multi-ethnic Asian country. Am J Gastroenterol 2006; 101: 1430-6.

7. Yee YK, Cheung TK, Chan AO, Yuen MF, Wong BC. Decreasing trend of esophageal adenocarcinoma in Hong Kong. Cancer Epidemiol Biomarkers Prev 2007; 16: 2637-40.

8. Shibata A, Matsuda T, Ajiki W, Sobue T. Trend in incidence of adenocarcinoma of the esophagus in Japan, 1993-2001. Jpn J Clin Oncol 2008; 38: 464-8.

9. Lu CL, Lang HC, Luo JC, Liu CC, Lin HC, Chang FY, Lee SD. Increasing trend of the incidence of esophageal squamous cell carcinoma, but not adenocarcinoma, in Taiwan. Cancer Causes Control 2010; 21: 269-74.

10. Sun ZG, Song GM, Zhang M, Wang Z, Ni ZH. Clinical study on magnesium, copper and chrome levels in patients with oesophageal squamous cell carcinoma. Contemp Oncol (Pozn) 2011; 15: 257-60.

11. Pedram A, Mahmodlou R, Enshayi A, Sepehrvand N. Esophageal cancer in northwestern Iran. Indian I Cancer 2011; 48: 165-9.

12. Enzinger PC, Mayer RJ. Esophageal cancer. N Engl J Med 2003; 349: 2241-52.

13. FitzGerald SC, Al Sahaf M, Furlong H, Pennycooke K, Healy C, Walsh TN. Lack of awareness of oesophageal carcinoma among the public in Ireland. Ir J Med Sci 2008; 177: 151-4.

14. Gottwald L, Spych M, Moszyńska-Zielińska M, et al. Clinical analysis of patients with central nervous system metastases from breast cancer. Prz Menopauzalny 2012; 2: 98-102.

15. Turkyilmaz A, Eroglu A, Subasi M, Karaoglanoglu N. Clinicopathological features and prognosis of esophageal cancer in young patients. Is there a difference in outcome? Dis Esophagus 2009; 22: 211-5.

16. Cummings LC, Cooper GS. Descriptive epidemiology of esophageal carcinoma in the Ohio Cancer Registry. Cancer Detect Prev 2008; 32: 87-92.

17. Bouvier AM, Binquet C, Gagnaire A, Jouve JL, Faivre J, Bedenne L. Management and prognosis of esophageal cancers: has progress been made? Eur J Cancer 2006; 42: 228-33.

18. Ishikawa H, Sakurai H, Yamakawa M, et al. Clinical outcomes and prognostic factors for patients with early esophageal squamous cell carcinoma treated with definitive radiation therapy alone. J Clin Gastroenterol 2005; 39: 495-500.

19. Yamada K, Murakami M, Okamoto Y, Okuno Y, Nakajima T, Kusumi F, Takakuwa H, Matsusue S. Treatment results of radiotherapy for carcinoma of the cervical esophagus. Acta Oncol 2006; 45: 1120-5.

20. Fang FM, Tsai WL, Chiu HC, Kuo WR, Hsiung CY. Quality of life as a survival predictor for esophageal squamous cell carcinoma treated with radiotherapy. Int J Radiat Oncol Biol Phys 2004; 58: 1394-404.

21. Edge SB, Byrd DR, Compton CC. AJCC Cancer Staging Manual. $7^{\text {th }}$ ed. New York: Springer-Verlag 2009; 103-15.

22. Mariette C, Piessen G, Briez N, Triboulet JP. The number of metastatic lymph nodes and the ratio between metastatic and examined lymph nodes are independent prognostic factors in esophageal cancer regardless of neoadjuvant chemoradiation or lymphadenectomy extent. Ann Surg 2008; 247: 365-71.

23. Greenstein AJ, Litle VR, Swanson SJ, Divino CM, Packer S, Wisnivesky JP. Prognostic significance of the number of lymph node metastases in esophageal cancer. J Am Coll Surg 2008; 206: 239-46.

24. Wang J, Liu F, Gao H, Wei W, Zhang X, Liang Y, Cheng Y. The symptom-to-treatment delay and stage at the time of treatment in cancer of esophagus. Jpn J Clin Oncol 2008; 38: 87-91.

25. Martin LG, Young S, Sue-Ling H, Johnston D. Delays in the diagnosis of oesophagogastric cancer: A consecutive case series. Br Med J 1997; 314: 467-71.

26. Rothwell JF, Feehan E, Reid I, Walsh TN, Hennessy TP. Delay in treatment for oesophageal cancer. Br J Surg 1997; 84: 690-3.

27. Tentzeris V, Lake B, Cherian T, Milligan J, Sigurdsson A. Poor awareness of symptoms of oesophageal cancer. Interact Cardiovasc Thorac Surg 2011; 12: 32-4.

28. Subasinghe D, Samarasekera DN. Delay in the diagnosis of esophageal carcinoma: Experience of a single unit from a developing country. Indian J Cancer 2010; 47: 151-5.

29. Gibbs JF, Rajput A, Chadha KS, Douglas WG, Hill H, Nwogu C, Nava HR, Sabel MS. The changing profile of esophageal cancer 
presentation and its implication for diagnosis. J Natl Med Assoc 2007; 99: 620-6.

30. Yang HX, Xu Y, Fu JH, Wang JY, Lin P, Rong TH. An evaluation of the number of lymph nodes examined and survival for node-negative esophageal carcinoma cata from China. Ann Surg Oncol 2010; 17 : 1901-11.

31. Lizuka T, Isono K, Kakegawa T, Watanabe H. Parameters linked to ten-year survival in Japan of resected esophageal carcinoma. Japanese Committee for Registration of Esophageal Carcinoma Cases. Chest 1989; 96: 1005-11.

32. Eloubeidi MA, Desmond R, Arguedas MR, Reed CE, Wilcox CM. Prognostic factors for the survival of patients with esophageal carcinoma in the U.S.: the importance of tumor length and lymph node status. Cancer 2002; 95: 1434-43.

\section{Address for correspondence}

\section{Shu-Chang Xu}

Department of Gastroenterology,

Tongji Hospital Affiliated to Tongii University,

No. 389, Xincun Road

Shanghai 200065, China

tel. +86 021-66111278

fax 021-56050502;

e-mail: xsc-students@hotmail.com

\section{Heng-Jun Gao}

National Engineering Centre for Biochip at Shanghai

No. 151, Libing Road

Shanghai 201203, China

tel.+86 021-51371308

fax 021-51320287

e-mail: hengjun_gao@shbiochip.com

Submitted: 6.09 .2013

Accepted: $\quad 14.11 .2013$ 